\title{
Candidemia epidemiology and susceptibility profile in the largest Brazilian teaching hospital complex
}

\begin{abstract}
Introduction: Although the spectrum of fungi causing bloodstream fungal infections continues to expand, Candida spp. remains responsible for the majority of these cases. Objective: The purpose of this study was to characterize the candidemia epidemiology, species distribution and antifungal susceptibility patterns at a Brazilian tertiary teaching public hospital with 2,500 beds. Methods: Records from the microbiology laboratory were used to identify patients with positive blood cultures during 2006. The in vitro activity of amphotericin B, caspofungin, itraconazole, fluconazole, voricanozole, and posaconazole were determined using the Etest method. Results: One hundred and thirty-six cases of candidemia were identified and 100 strains were available for antifungal susceptibility testing. The overall incidence of candidemia was 1.87 cases/1.000 admissions and 0.27 cases/1.000 patient-days. Among the patients, $58.1 \%$ were male, and the median age was 40 years old. C. albicans was the most common species $(52.2 \%)$, followed by $C$. parapsilosis $(22.1 \%)$, C. tropicalis (14.8\%), and C. glabrata (6.6\%). All strains were susceptible to amphotericin B with a $\mathrm{MIC}_{90}$ of $0.5 \mu \mathrm{g} / \mathrm{mL}$. Overall susceptibility for voriconozole, fluconazole, and caspofungin was $\geq 97 \%$ with a $\mathrm{MIC}_{90}$ of $0.064,4.0$ and $1.0 \mu \mathrm{g} / \mathrm{mL}$, respectively. For itraconazole the susceptibility rate was $81 \%$ with a $\mathrm{MIC}_{90}$ of $0.5 \mu \mathrm{g} / \mathrm{mL}$. Posaconazole also demonstrated good in vitro activity with a $\mathrm{MIC}_{90}$ of $0.25 \mu \mathrm{g} / \mathrm{mL}$. Conclusion: This is the first antifungal susceptibility report in our institution.
\end{abstract}

Keywords: candidemia, Candida spp, susceptibility testing, Candida epidemiology, Candida Etest, antifungal susceptibility profile, Candida antifungal agents, azoles.

[Braz J Infect Dis 2010;14(5):441-448] @Elsevier Editora Ltda.
Authors

Adriana Lopes Motta

Gisele Madeira Duboc de Almeida $^{1}$

João Nóbrega de Almeida Júnior $^{1}$

Marcelo Nascimento

Burattini $^{1}$

Flávia Rossi ${ }^{1}$

${ }^{1}$ Microbiology Laboratory, Division of Central

Laboratory, LIM 03

Department of Pathology,

Universidade de São Paulo,

São Paulo, Brazil.

\section{INTRODUCTION}

During the past decades, publications have documented an increase in health care associated fungal infections in different patient populations. ${ }^{1}$ A recent study of the epidemiology of sepsis found that the annual number of cases caused by fungal organisms in the United States increased by 207\% between 1979 and 2000..$^{2}$ Although the spectrum of fungi causing bloodstream infections has increased, Candida spp. remains the most common agent of such infections accounting for approximately $80 \%$ of cases. ${ }^{3-6}$ As candidemia carries a high morbidity and mortality rate ${ }^{1,4}$ various antifungal agents have been preemptively or prophylactically used in routine care of high-risk patient populations. ${ }^{1,7}$ However, the widespread use of antifungal agents raises concerns about their potential ecological effects in selecting and spreading resistant fungal strains or species. There have been many reports of breakthrough fungal infections with strains showing intrinsic or acquired resistance to the exposed drug. ${ }^{8-12}$ The antifungal susceptibility testing (AFST) helps clinicians in choosing the appropriate antifungal therapy. Currently, the AFST reference methodology for Candida spp. is a broth dilution proposed by the Clinical Laboratory Standards Institute (CLSI). Susceptibility breakpoints are available for fluconazole, itraconazole, voriconozole, and echinocandins. ${ }^{13}$ This methodology is extremely time consuming and difficult to perform in routine practice at clinical laboratories.
Submitted on: 3/5/2010 Approved on: 7/31/2010

Correspondence to: Adriana Lopes Motta Rua Capote Valente 668 complement apt 32, São Paulo, SP- Brazil. CEP: 05409-002 Phone/fax:

+55-11-30696348

E-mail:

drilomotta@hotmail.com

Financial Support:

Fundação de Amparo à Pesquisa do Estado de São Paulo (FAPESP). 
AFST commercial systems like Etest strips (AB Biodisk, Sweden) have good categorical consistency with the reference method and is a validated alternative methodology to perform routine AFST. ${ }^{14-20}$

In Brazil candidemia data and antifungal susceptibility patterns of associated strains are still sparse. In our institution we record the occurrence of cases candidemia of since 1996 (data not shown). In 2006, as there was an increase in the occurrence of Candida from blood cultures, we then started a project to monitor the resistance patterns during this period. The aim of this study was to evaluate the epidemiology of candidemia, species distribution, and susceptibility profile over one year at our institution, the largest Brazilian tertiary teaching hospital.

\section{METHODS}

The study was conducted at the Hospital das Clínicas da Faculdade de Medicina da Universidade de São Paulo (HC), a 2,500 bed tertiary teaching complex, located in the city of São Paulo, Brazil, that provides care for a varied population, including immunosuppressed patients. The HC Complex is mainly comprised of five hospitals attached to the Universidade de São Paulo Medical School, including a general hospital, and other facilities specialized in heart diseases, a pediatric hospital, an orthopedic and a psychiatric hospital, with overall 1,975 ward beds and 325 intensive care unit (ICU) beds.

\section{Case Definition}

Records from the microbiology laboratory were used to identify patients with positive peripheral blood cultures for Candida species from January $1^{\text {st }}$ to December $31^{\text {st }}$, 2006. Candidemia was defined as the isolation of Candida spp. from blood culture (one isolate per patient). A new episode was considered as the identification of the same Candida species more than 30 days after the first positive blood culture or finding a new Candida species. Cases were reviewed using a standardized data extraction form observing demographic data, underlying diseases, and patient hospital location at the time of the first positive blood culture.

\section{Organism identification}

Blood cultures were monitored using an automated culture system (Bactec 9240 System, Becton, Dickinson, USA). Isolates were stored frozen in BHI with $20 \%$ glycerol and $0.2 \%$ agar at $-70^{\circ} \mathrm{C}$. Stored strains were subcultured onto potato dextrose agar (Remel, USA) and chromogenic media for Candida species (CHROMagar Microbiology, USA) to ensure purity. Germ tube test, growth at $42^{\circ} \mathrm{C}$, assimilation test by API 20C AUX (bioMerieux, French) and microscopy features in cornmeal
Tween 80 medium (Oxoid, USA) were used for specie identification confirmation.

\section{Susceptibility testing}

Antifungal susceptibility testing was performed using the Etest method (AB BIODISK, Sweden) according to the manufacturer's instructions. The following drugs were tested: amphotericin B, caspofungin, fluconazole, itraconazole, voriconazole, and posaconazole. A $150 \mathrm{~mm}$ commercial agar plate (Probac, Brazil) containing RPMI 1640 medium supplemented with $2 \%$ glucose buffered with MOPS in a pH of 7.0 was used. The inocula suspension was adjusted with a spectrophotometer to match the transmittance produced by a 0.5 McFarland density standard at a $530 \mathrm{~nm}$ wavelength. The agar surface was inoculated using a nontoxic swab according to the manufactures instructions. Etest strips were applied after excess moisture was absorbed and the agar surface was completely dry. The plates were incubated at $35^{\circ} \mathrm{C}$ and the MIC $(\mu \mathrm{g} / \mathrm{mL})$ was read after 24 hours. The MIC $(\mu \mathrm{g} / \mathrm{mL})$ was read as the lowest concentration at which the border of the elliptical zone of growth inhibition intersected the scale on the Etest strip. For the azoles and caspofungin, an $80 \%$ growth inhibition was used as the MIC endpoint, and for amphotericin B, nearly complete growth inhibition (100\%) was used according to manufacture instructions. For MICs that yielded results falling in between conventional serial twofold dilution, the next highest dilution was assigned.

\section{Category MIC breakpoints (BP)}

Interpretations for fluconazole, itraconazole, voriconazole and caspofungin were according M27A3, 2008 CLSI document, 2008. ${ }^{13}$ Interpretative breakpoints have not yet been established for amphotericin B, but breakpoints proposed by Nguyen et al. were used to classified strains..$^{21}$ For posaconazole there is not an established interpretative breakpoint yet.

\section{Quality control}

Quality control was assured by testing the strains recommended by CLSI Candida krusei ATCC 6258 and Candida parapsilosis ATCC 22019 in each batch of MIC testing. ${ }^{13}$

\section{Statistical analysis}

The incidence rates were calculated as the number of candidemia episodes per 1,000 admissions and per 1,000 patient-days. Categorical data were analyzed using Chisquare and Fisher's exact tests, as appropriate. A p value $\leq 0.05$ was considered statistically significant. Data analyses were performed by Epi-Info 6.04 software CDC (Centers for Disease Control and Prevention). 


\section{RESULTS}

During 2006, the prevalence of fungi and Candida spp. in positive blood cultures were $4 \%$ and $3.5 \%$ respectively, being $86.1 \%$ of fungemia related to Candida species. One hundred and thirty six candidemia episodes were identified in 132 patients. The overall incidence of candidemia was 1.87 per $1,000 \mathrm{admissions}$ and 0.27 per 1,000 patient days. There was a wide variation of incidence rates among hospitals from the HC complex ranging from 0.0 to 7.6 cases per 1,000 admissions (Table 1). Seventy seven patients (59.9\%) were male, and the median age was 40 years old ( $0-87$ years). Fifty one patients were children, and $62.7 \%$ had less than one year old. Among adult patients ( $>16$ years old) the median age was 54 years, and 3 months old among children ( $0-16$ years old); $91 \%$ of patients were hospitalized. Of these, $56.5 \%$ were in clinical wards, $26.3 \%$ in intensive care units, and $17.2 \%$ in surgical wards. The majority of patients had an underlying disease, being malignancy the most frequent one $(32.5 \%)$ (Table 2). Among children younger than one year, prematurity was observed in $56.2 \%$ of candidemia cases.

Table 1. Candidemia: Incidence rates and species distribution in different hospitals from Hospital das Clínicas complex from January to December 2006

\begin{tabular}{|c|c|c|c|c|c|c|c|c|c|c|c|c|c|c|}
\hline \multirow{3}{*}{$\begin{array}{l}\text { Candida spp } \\
\text { C. albicans (66) }\end{array}$} & \multirow{2}{*}{\multicolumn{2}{|c|}{$\begin{array}{l}\text { General hosp } \\
\text { ADM Pat/day }\end{array}$}} & \multirow{2}{*}{\multicolumn{2}{|c|}{$\begin{array}{r}\text { Pediatric hosp } \\
\text { ADM Pat/day }\end{array}$}} & \multicolumn{2}{|c|}{ Cardiac hosp } & \multirow{2}{*}{\multicolumn{2}{|c|}{$\begin{array}{l}\text { Ortopedic hosp } \\
\text { ADM Pat/day }\end{array}$}} & \multirow{2}{*}{\multicolumn{2}{|c|}{$\begin{array}{l}\text { Axiliary } 1 \text { hosp } \\
\text { ADM Pat/day }\end{array}$}} & \multicolumn{4}{|c|}{ Axiliary 2 hosp Total } \\
\hline & & & & & ADM & Pat/day & & & & & $\mathrm{ADM}$ & Pat/day & $\mathrm{ADM}$ & Pat/day \\
\hline & 1.01 & 0.15 & 3.63 & 0.55 & 0.91 & 0.31 & 0.38 & 0.05 & 0 & 0 & 2.37 & 0.03 & 1.0 & 0.17 \\
\hline C. parapsilosis (26) & 0.27 & 0.05 & 2.90 & 0.44 & 0.30 & 0.10 & 0 & 0 & 0.39 & 0.03 & 0 & 0 & 0.37 & 70.05 \\
\hline C. tropicalis (18) & 0.25 & 0.04 & 0.73 & 0.11 & 0.38 & 0.12 & 0 & 0 & 0.39 & 0.03 & 0 & 0 & 0.28 & 30.04 \\
\hline C. glabrata (9) & 0.20 & 0.03 & 0 & 0 & 0.08 & 0.02 & 0 & 0 & 0 & 0 & 0 & 0 & 0.14 & $4 \quad 0.02$ \\
\hline C. krusei (2) & 0.03 & 0 & 0 & 0 & 0.08 & 0.02 & 0 & 0 & 0 & 0 & 0 & 0 & 0.03 & 0.004 \\
\hline C. guilliermondii (1) & 0.03 & 0 & 0 & 0 & 0 & 0 & 0 & 0 & 0 & 0 & 0 & 0 & 0.02 & 0.002 \\
\hline C. lusitaneae (1) & 0.03 & 0 & 0 & 0 & 0 & 0 & 0 & 0 & 0 & 0 & 0 & 0 & 0.02 & 0.002 \\
\hline C. pelliculosa (1) & 0 & 0 & 0 & 0 & 0 & 0 & 0.18 & 0.03 & 0 & 0 & 0 & 0 & 0.02 & 0.002 \\
\hline C. utilis (1) & 0.03 & 0 & 0 & 0 & 0 & 0 & 0 & 0 & 0 & 0 & 0 & 0 & 0.02 & 0.002 \\
\hline Total (125) & 1.85 & 0.27 & 7.26 & 1.10 & 1.75 & 0.57 & 0.56 & 0.08 & 0.78 & 0.06 & 2.37 & 0.03 & 1.87 & 0.27 \\
\hline $\begin{array}{l}\text { Admission (ADM) } \\
\text { Patient days (pat/da }\end{array}$ & $\begin{array}{r}39 \\
\text { ay) } 26\end{array}$ & $\begin{array}{l}397 \\
, 774\end{array}$ & & 8,855 & $\begin{array}{l}13,1 \\
40,5\end{array}$ & & & $\begin{array}{l}313 \\
369\end{array}$ & & $\begin{array}{l}, 563 \\
3,936\end{array}$ & & $\begin{array}{l}422 \\
, 887\end{array}$ & & $\begin{array}{l}5,276 \\
5,546\end{array}$ \\
\hline
\end{tabular}

Hosp, hospital.

Table 2. Candidemia in Hospital das Clínicas complex - Underline disease and distribution among C. albicans and other Candida species

\begin{tabular}{|lcccc|}
\hline Underline disease & C. albicans $\mathbf{( 7 1 )}$ & non albicans $\boldsymbol{C}$ (65) & Total & p-value \\
\hline Solid Cancer & 14 & 11 & 25 & 0.67 \\
\hline Prematurity & 9 & 9 & 18 & 0.84 \\
\hline Hematologic malignancy & 7 & 10 & 17 & 0.33 \\
\hline Cardiac disease & 8 & 6 & 14 & 0.69 \\
\hline Neurologic disease & 4 & 4 & 8 & 0.89 \\
\hline Organ transplant & 4 & 3 & 7 & 0.79 \\
\hline Autoimmune disease & 3 & 3 & 6 & 0.91 \\
\hline Gastrointestinal disease & 4 & 2 & 6 & 0.47 \\
\hline Pulmonary disease & 4 & 1 & 5 & 0.20 \\
\hline Vascular disease & 1 & 3 & 4 & 0.27 \\
\hline HIV & 2 & 2 & 4 & 0.93 \\
\hline Politrauma & 3 & 1 & 4 & 0.35 \\
\hline Genetic - Hereditary disease & 2 & 1 & 3 & 0.61 \\
\hline Skin and soft tissue disease & 1 & 4 & 5 & 0.14 \\
\hline Renal disease & 2 & 0 & 2 & 0.17 \\
\hline Tuberculosis & 1 & 0 & 1 & 0.33 \\
\hline Diabetes Mellitus & 1 & 0 & 1 & 0.33 \\
\hline Non evaluated & 1 & 5 & 6 & NA \\
\hline
\end{tabular}


The most frequent specie was C. albicans $(52.2 \%)$, followed by C. parapsilosis (22.1\%), C. tropicalis (14.7\%), C. glabrata (6.6\%), and C. krusei (1.6\%). Table 3 summarizes the species' distribution. Differences in species distribution among non-C. albicans were seen in the facility type (Table 1), patient location, and age group (Table 4).

Antifungal susceptibility testing (AFST) was performed among 100 Candida spp. (56 C. albicans, 21 C. parapsilosis, 14 C. tropicalis, 4 C. glabrata, 2 C. krusei, and 1 isolate each of C. guilliermondii, C. lusitaneae, and C. pelliculosa) as 36 isolates lost viability. Table 5 summarizes in vitro Candida spp. susceptibilities rates, MIC, $\mathrm{MIC}_{50}$ and $\mathrm{MIC}_{90}$ ranges.

Overall susceptibility to amphotericin B was $100 \%$ $\left(\mathrm{MIC}_{50} 0.125 \mu \mathrm{g} / \mathrm{mL} / \mathrm{MIC}_{90} 0.5 \mu \mathrm{g} / \mathrm{mL}\right.$ ), for voriconozole $\left(\mathrm{MIC}_{50} 0.008 \mu \mathrm{g} / \mathrm{mL} / \mathrm{MIC}_{90} 0.064 \mu \mathrm{g} / \mathrm{mL}\right.$ ), fluconazole
$\left(\mathrm{MIC}_{50} 0,25 \mu \mathrm{g} / \mathrm{mL} / \mathrm{MIC}_{90} 4 \mu \mathrm{g} / \mathrm{mL}\right.$ ), and caspofungin $\left(\mathrm{MIC}_{50} 0.125 \mu \mathrm{g} / \mathrm{mL} / \mathrm{MIC}_{90} 1 \mu \mathrm{g} / \mathrm{mL}\right.$ ) were $\geq 97 \%$ for itraconazole $\left(\mathrm{MIC}_{50} 0.032 \mu \mathrm{g} / \mathrm{mL} / \mathrm{MIC}_{90} 0.5 \mu \mathrm{g} / \mathrm{mL}\right)$; the susceptibility rate was $81 \%$. Decreased susceptibility to caspofungin was seen with $9.5 \%$ of C. parapsilosis $(2 / 21$ isolates with MICs $4 \mu \mathrm{g} / \mathrm{mL})$. All C. albicans, $C$. tropicalis and C. parapsilosis. C. glabrata and C. krusei were susceptible to fluconazole, but one of each, had decreased susceptibility to fluconazole. Decreased susceptibility to itraconazole was seen in $12.5 \%$ of C. albicans; $23.8 \%$, of C. parapsilosis; $21.4 \%$ of C. tropicalis, $75 \%$ ofC. glabrata (3/4 isolates) and 100\% of C. gulliermondii ( $1 / 1$ isolate). Voriconazole had good in vitro activity, but a MIC of $4 \mu \mathrm{g} / \mathrm{mL}$ in one C. glabrata isolate was recorded. Posaconazole exhibited low MICs for all isolates, except one C. gulliermondii $(32 \mu \mathrm{g} / \mathrm{mL})$ and one C. glabrata $(4 \mu \mathrm{g} / \mathrm{mL})$.

Table 3. Distribution of Candida species isolates from blood culture in Hospital das Clínicas complex from January to December 2006

\begin{tabular}{lcc|}
\hline Candida spp & $\mathbf{n}$ & $\%$ \\
\hline C. albicans & 71 & $52.2 \%$ \\
\hline C. parapsilosis & 30 & $22.1 \%$ \\
\hline C. tropicalis & 20 & $14.8 \%$ \\
\hline C. glabrata & 9 & $6.6 \%$ \\
\hline C. krusei & 2 & $1.5 \%$ \\
\hline C. guilliermondii & 1 & $0.7 \%$ \\
\hline C. lusitaneae & 1 & $0.7 \%$ \\
\hline C. pelliculosa & 1 & $0.7 \%$ \\
\hline C. utilis & 1 & $0.7 \%$ \\
\hline Total & 136 & $100.0 \%$ \\
\hline
\end{tabular}

Table 4. Distribution of Candida species and candidemia cases by age group in Hospital das Clínicas complex from January to December 2006

\begin{tabular}{|c|c|c|c|c|c|c|c|c|c|c|}
\hline \multirow[t]{2}{*}{ Candida spp } & \multicolumn{2}{|c|}{$<1$} & \multicolumn{2}{|c|}{$>1$ to $<15$} & \multicolumn{2}{|c|}{$>16$ to $<64$} & \multicolumn{2}{|c|}{$>65$} & \multicolumn{2}{|c|}{ Total } \\
\hline & $\mathbf{n}$ & $\%$ & $\mathbf{n}$ & $\%$ & $\mathbf{n}$ & $\%$ & $\mathbf{n}$ & $\%$ & $\mathbf{n}$ & $\%$ \\
\hline $\begin{array}{l}\text { Distribution of } \\
\text { candidemias by age groups }\end{array}$ & 32 & $23.5 \%$ & 19 & $14.0 \%$ & 65 & $47.8 \%$ & 20 & $14.7 \%$ & 136 & $100.0 \%$ \\
\hline C. albicans (71) & 16 & $50.0 \%$ & 9 & $47.4 \%$ & 36 & $55.4 \%$ & 10 & $50.0 \%$ & 71 & $52.2 \%$ \\
\hline C. parapsilosis (30) & 15 & $46.9 \%$ & 4 & $21.1 \%$ & 9 & $13.9 \%$ & 2 & $13.9 \%$ & 30 & $22.1 \%$ \\
\hline C. tropicalis (20) & 0 & $0.0 \%$ & 5 & $26.3 \%$ & 10 & $15.4 \%$ & 5 & $25.0 \%$ & 20 & $14.7 \%$ \\
\hline C. glabrata (9) & 1 & $3.1 \%$ & 0 & $0.0 \%$ & 6 & $9.2 \%$ & 2 & $10.0 \%$ & 9 & $6.6 \%$ \\
\hline C. krusei (2) & 0 & $0.0 \%$ & 0 & $0.0 \%$ & 2 & $3.1 \%$ & 0 & $0.0 \%$ & 2 & $1.6 \%$ \\
\hline C. guilliermondii (1) & 0 & $0.0 \%$ & 0 & $0.0 \%$ & 0 & $0.0 \%$ & 1 & $5.0 \%$ & 1 & $0.7 \%$ \\
\hline C. lusitaneae (1) & 0 & $0.0 \%$ & 1 & $5.2 \%$ & 0 & $0.0 \%$ & 0 & $0.0 \%$ & 1 & $0.7 \%$ \\
\hline C. pelliculosa (1) & 0 & $0.0 \%$ & 0 & $0.0 \%$ & 1 & $1.5 \%$ & 0 & $0.0 \%$ & 1 & $0.7 \%$ \\
\hline C. utilis (1) & 0 & $0.0 \%$ & 0 & $0.0 \%$ & 1 & $1.5 \%$ & 0 & $0.0 \%$ & 1 & $0.7 \%$ \\
\hline Total (136) & 32 & $100.0 \%$ & 19 & $100.0 \%$ & 65 & $100.0 \%$ & 20 & $100.0 \%$ & 136 & $100.0 \%$ \\
\hline
\end{tabular}


Table 5. Antifungal susceptbility testing of 100 Candida spp. isolated from blood culture in Hospital das Clínicas complex from January to December of 2006

\begin{tabular}{|c|c|c|c|c|c|c|}
\hline $\begin{array}{l}\text { Specie (n) } \\
\text { Drogas }\end{array}$ & $\begin{array}{c}\text { S } \\
\text { n (\%) }\end{array}$ & $\begin{array}{l}\text { SDD } \\
\text { n (\%) }\end{array}$ & $\begin{array}{c}\text { R } \\
\text { n (\%) }\end{array}$ & $\begin{array}{l}\mathrm{MIC}_{90} \\
\mu \mathrm{g} / \mathrm{mL}\end{array}$ & $\begin{array}{l}\mathrm{MIC}_{50} \\
\mu \mathrm{g} / \mathrm{mL}\end{array}$ & $\begin{array}{l}\text { Range } \\
\mu \mathrm{g} / \mathrm{mL}\end{array}$ \\
\hline \multicolumn{7}{|l|}{ C. albicans (56) } \\
\hline Amphotericin B & $56(100)$ & $0(0)$ & $0(0)$ & 0.5 & 0.125 & $0.016-1$ \\
\hline Caspofungin & $56(100)$ & $0(0)$ & $0(0)$ & 1 & 0.125 & $0.016-1$ \\
\hline Fluconazole & $56(100)$ & $0(0)$ & $0(0)$ & 0.5 & 0.125 & $0.125-4$ \\
\hline Itraconazole & $49(87.5)$ & $6(10.7)$ & $1(1.8)$ & 0.25 & 0.016 & $0.008-1$ \\
\hline Voriconazole & $56(100)$ & $0(0)$ & $0(0)$ & 0.064 & 0.008 & $0.008-0.125$ \\
\hline Posaconazole & $\mathrm{NC}$ & $\mathrm{NC}$ & $\mathrm{NC}$ & 0.064 & 0.008 & $0.008-0.064$ \\
\hline \multicolumn{7}{|l|}{ C. parapsilosis (21) } \\
\hline Amphotericin B & $21(100)$ & $0(0)$ & $0(0)$ & 0.125 & 0.125 & $0.032-0.5$ \\
\hline Caspofungin & $19(90.5)$ & $0(0)$ & $2(9.5)$ & 2 & 1 & $0.064-4$ \\
\hline Fluconazole & $21(100)$ & $0(0)$ & $0(0)$ & 4 & 0.5 & $0.125-8$ \\
\hline Itraconazole & $16(76.2)$ & $3(14.3)$ & $2(9.5)$ & 0.5 & 0.032 & $0.008-1$ \\
\hline Voriconazole & $21(100)$ & $0(0)$ & $0(0)$ & 0.064 & 0.016 & $0.008-0.125$ \\
\hline Posaconazole & NA & NA & NA & 0.25 & 0.016 & $0.016-0.5$ \\
\hline \multicolumn{7}{|l|}{ C. tropicalis (14) } \\
\hline Amphotericin B & $14(100)$ & $0(0)$ & $0(0)$ & 1 & 0.125 & $0.016-1$ \\
\hline Caspofungin & $14(100)$ & $0(0)$ & $0(0)$ & 1 & 0.125 & $0.064-2$ \\
\hline Fluconazole & $14(100)$ & $0(0)$ & $0(0)$ & 1 & 0.25 & $0.125-1$ \\
\hline Itraconazole & $11(78.6)$ & $1(7.1)$ & $2(14.3)$ & 1 & 0.016 & $0.008-32$ \\
\hline Voriconazole & $14(100)$ & $0(0)$ & $0(0)$ & 0.032 & 0.016 & $0.008-0.032$ \\
\hline Posaconazole & NA & NA & NA & 0.25 & 0.064 & $0.008-0.125$ \\
\hline \multicolumn{7}{|l|}{ C. glabrata (4) } \\
\hline Amphotericin B & $4(100)$ & $0(0)$ & $0(0)$ & 1 & - & $0.125-1$ \\
\hline Caspofungin & $4(100)$ & $0(0)$ & $0(0)$ & 1 & - & $0.125-1$ \\
\hline Fluconazole & $2(50)$ & $1(25.0)$ & $1(25.0)$ & 256 & - & $0.125-256$ \\
\hline Itraconazole & $1(25.0)$ & $0(0)$ & $3(75.0)$ & 32 & - & $0.016-32$ \\
\hline Voriconazole & $3(75.0)$ & $0(0)$ & $1(25.0)$ & 0.125 & - & $0.008-4$ \\
\hline Posaconazole & NA & NA & NA & 32 & - & $0.008-32$ \\
\hline \multicolumn{7}{|l|}{ C. krusei (2) } \\
\hline Amphotericin B & $2(100)$ & $0(0)$ & $0(0)$ & 0.25 & - & $0.032-0.25$ \\
\hline Caspofungin & $2(100)$ & $0(0)$ & $0(0)$ & 0.5 & - & $0.064-0.5$ \\
\hline Fluconazole & $1(50)$ & $0(0)$ & $1(50)$ & 64 & - & $0.125-64$ \\
\hline Itraconazole & $2(100)$ & $0(0)$ & $0(0)$ & 0.125 & - & $0.016-0.125$ \\
\hline Voriconazole & $2(100)$ & $0(0)$ & $0(0)$ & 0.125 & - & $0.008-0.125$ \\
\hline Posaconazole & NA & NA & NA & 0.25 & - & $0.064-0.25$ \\
\hline \multicolumn{7}{|l|}{ Others (3) } \\
\hline Amphotericin B & $3(100)$ & $0(0)$ & $0(0)$ & 0.5 & - & $0.016-0.5$ \\
\hline Caspofungin & $3(100)$ & $0(0)$ & $0(0)$ & 2 & - & $0.016-2$ \\
\hline Fluconazole & $3(100)$ & $0(0)$ & $0(0)$ & 4 & - & $0.032-4$ \\
\hline Itraconazole & $2(66.7)$ & $0(0)$ & $1(33.3)$ & 32 & - & $0.008-32$ \\
\hline Voriconazole & $3(100)$ & $0(0)$ & $0(0)$ & 0.064 & - & $0.008-0.064$ \\
\hline Posaconazole & NA & NA & NA & 4 & - & $0.008-4$ \\
\hline \multicolumn{7}{|l|}{ Total (100) } \\
\hline Amphotericin B & $100(100)$ & $0(0)$ & $0(0)$ & 0.5 & 0.125 & $0.016-1$ \\
\hline Caspofungin & $98(98.0)$ & $0(0)$ & $2(2.0)$ & 1 & 0.125 & $0.016-4$ \\
\hline Fluconazole & $97(97.0)$ & $1(1.0)$ & $2(2.0)$ & 4 & 0.25 & $0.125-256$ \\
\hline Itraconazole & $81(81.0)$ & $10(10)$ & $9(9.0)$ & 0.5 & 0.032 & $0.008-32$ \\
\hline Voriconazole & 99 (99.0) & $0(0)$ & $1(1.0)$ & 0.064 & 0.008 & $0.008-4$ \\
\hline Posaconazole & NA & NA & NA & 0.25 & 0.016 & $0.008-32$ \\
\hline
\end{tabular}

Note: S, suceptible; SDD, susceptible dose dependent; R, resistant. Breakpoints according to CLSI M27 A3.

NA, categorical results not applicable. Others $C$ guilliermondii; $C$. lusitaneae; $C$. pelliculosa. MIC 90 was not calculated when the number of isolates tested was $<10$. 


\section{DISCUSSION}

Candidemia remains a persistent challenge in many hospitals worldwide leading to significant mortality and overload of healthcare costs. There is a wide variation in the incidence of candidemia reported in the literature underscoring the need for local and global epidemiological studies.

The prevalence of Candida spp. among blood cultures, in our study period, was $3.5 \%$, being the ninth most common isolated microorganism from blood cultures, differing from other studies were this microorganism was listed as the $5^{\text {th }}$ most frequent one. . $^{1,4,6}$

The overall incidence rate ( 1.87 cases/1,000 admissions) was similar to previous Brazilian reports with rates ranging from 1.66 to 2.49 cases per 1,000 admissions when comparing different hospitals from the HCFMUSP complex. ${ }^{6,22}$ Important differences were seen among the hospitals, probably reflecting distinct patient populations and differences in risk factors. Reports from Canada, USA and Europe showed a much lower incidence in candidemia rates, ranging from 0.045 to 0.38 cases per 1,000 admissions. ${ }^{23,27}$ The high rates of candidemia in Brazilian public hospitals were highlightened by Colombo et al. in a multicenter study and were multifactor related, such as difficulties in implementing hospital infection control measures, limited number of health care workers, and less aggressive antifungal prophylaxis practices. ${ }^{6,22}$

C. albicans was the specie most frequently isolated followed by C. parapsilosis, C. tropicalis and C. glabrata. This finding is consistent with national and Latin American studies. ${ }^{6,22,28,29}$ However, important differences of species distribution have been documented when evaluating by age group and clinical wards (nurses or ICU). Of note, C. parapsilosis was the most prevalent non-C. albicans species, probably because a high proportion of children younger than 1 year old accounted for almost $25 \%$ of cases. C. parapsilosis is commonly linked to prematurity, use of central venous catheter, and parenteral nutrition. ${ }^{1,30,32}$ Among patients with more than one year old C. tropicalis was the most common non-C. albicans species.

C. glabrata was the second non-C. albicans in ICU and deserves attention. C. glabrata and C. krusei have been an infrequent cause of candidemia in Brazil. Data from USA and European countries showed C. glabrata and C. parapsilosis as the most prevalent non-C. albicans species. ${ }^{1,4,23,24}$ The reasons for this variation are still not clear, but exposure to azoles, subjacent diseases, age group, ward location, and use of medical devices could explain these differences. ${ }^{1}$ Reports that evaluated the use of azoles as a risk factor associated with non- C. albicans candidemia that are intrinsically resistant or with reduced resistance to those drugs, such as C. krusei and C. glabrata, remain controversial. ${ }^{1,3,24,33-34}$ Girão et al. evaluated candidemia rates from one ICU in our hospital over a seven year period and did not find an increase in C. glabrata and/or C. krusei [incidence], despite increasing fluconazole use during this time. On the other hand, Pasqualotto et al. demonstrated an association between fluconazole use and higher incidence rates of C. glabrata fungemia. ${ }^{35}$

Antifungal susceptibility testing as a routine procedure, is an important tool to guide therapeutical choices and monitor local resistance. AFST strips by Etest are a validated agar based methodology that may be an alternative, because it is relatively easy to perform, with drug choice flexibility, and have very good consistency with the reference methodology. ${ }^{14-20}$ Occasionally category discordances between Etest and the microdilution method may occur due to the heteroresistance and trailing phenomenon, generating higher MICs. These factors were mainly observed with C. tropicalis for itraconazole and fluconazole, and with $C$. glabrata for fluconazole. Some authors demonstrated that heteroresistance detection was possible only with the use of Etest and that the reference methodology was unable to highlight this phenomenon. ${ }^{14}$

Similar to other national and international studies, antifungal resistance was a rare event. We did not find any Candida spp. with MICs $>1 \mu \mathrm{g} / \mathrm{mL}$ for amphotericin B, and $98 \%$ were susceptible to caspofungin, with two $C$. parapsilosis isolates with a MIC of $4 \mu \mathrm{g} / \mathrm{mL}$. Pfaller et al. evaluated 5,346 Candida spp. isolates and found a susceptibility rate of $99 \%$ to echinocandins. However, the MIC90 for C. parapsilosis was higher than other Candida species, and the reduced susceptibility mechanism is related to amino acid changes within the FKS1 in a hot spot region. ${ }^{36,38}$

Fluconazole resistant isolates were restricted to C. glabrata and C. krusei. The susceptibility profile to fluconazole was (97\%), similar to other Brazilian and Latin American studies. $6222,29,39-40,42$ European and North American studies have showed lower sensitivity, rates ranging from 86.6 to $95.8 \%{ }^{39,43}$ C. krusei, despite its known intrinsic resistance to fluconazole, may show false in vitro susceptibility and care should be taken to report those results.

For itraconazole, the percentage of non-susceptible isolates was 19\% (10\% SDD and 9\% R). Higher itraconazole MICs may be associated to technical errors in the MIC readings due to the trailing phenomenon. ${ }^{14}$ The trailing phenomenon is most often encountered with azoles and is characterized by incomplete growth inhibition. With appropriate training, reading errors should be minimal.

Voriconazole overall susceptibility was high and the only resistant strain was one C. glabrata (MIC of $4 \mu \mathrm{g} / \mathrm{mL}$ ) that showed cross-resistance to all azoles.

There are no official breakpoints for posaconazole, but the MIC90 $(0.25 \mu \mathrm{g} / \mathrm{mL})$ was much lower than previously reported by other authors. ${ }^{20,42,44}$ Of note, one isolate of C. glabrata and one of C. guilliermondii had a very high MIC $(4 \mu \mathrm{g} / \mathrm{mL})$. 
Candidemia has a high incidence in our institution and despite low resistant rates it poses a therapeutic challenge, especially among non-C. albicans species. Knowledge of local epidemiology and AFST profile may help physicians in selecting the appropriate therapy. Etest offers a validated alternative methodology for routine use in clinical laboratories, especially in countries where commercial microdilution panels are not available. Continuous surveillance to monitor trends in incidence, species distribution, and antifungal drug susceptibility profiles, should be performed at a local and global level, since epidemiological studies continue to reveal variations in candidemia epidemiology.

\section{REFERENCES}

1. Pfaller MA, Diekema DJ. Epidemiology of Invasive Candidiasis: a Persistent Public Health Problem. J Clin Microbiol Rev2007; 20:133-63.

2. Martin GS, Mannino DM, Eaton S et al. The epidemiology of sepsis in the United States from 1979 through 2000. N Engl J Med 2003; 348:1546-54.

3. Trick WE, Fridkin SK, Edwards JR et al. Secular trends of hospital Acquired Candidemia among Intensive Care Unit Patients in the United States during 1989-1999. Clin Infect Dis 2002; 35:627-30.

4. Eggimann P, Garbino J, Pittet D. Epidemiology of Candida species infection in critically ill immunosuppressed patients. The lancet Infect Dis 2003; 3:685-702.

5. Beck-Sague CM, Jarvis W. Secular Trends in the Epidemiology of Nosocomial Fungal Infections in the United States, 19801990. J Infect Dis 1993; 167:1247-51.

6. Colombo AL, Guimarães T, Silva LR et al. Prospective observational study of candidemia in São Paulo, Brazil: incidence rate, epidemiology, and predictors of mortality. Infect Control Hosp Epidemiol 2007; 28:570-6.

7. Cornelius JC, Staley B, Nguyen H. In vitro susceptibility of breakthrough Candida bloodstream isolates correlates with daily and cumulative doses of fluconazole. Antimicrob Agents Chemother 2006; 49:767-9.

8. Arendrup MC, Fuursted K, Gahrn-Hansen B et al. Seminational surveillance of fungemia in Denmark: notably high rates of fungemia and numbers of isolates with reduced azoles susceptibility. J Clin Microbiol 2005; 50:3496-8.

9. Moudgal V, Little T, Boikov D et al. Multiechinocandin- and multiazoleresistant Candida parapsilosis isolates serially obtained during therapy for prosthetic valve endocarditis. Antimicrob Agents Chemother 2005; 49:767-9.

10. Krogh-Madsen M, Arendrup MC, Heslet L et al. Aphotericin B and Caspofungin resistence in Candida glabrata isolates recovered from a critically ill patient. Clin Infect Dis 2006; 42:93844 .

11. Borst A, Raimer MT, Warnock DW et al. Rapid acquisition of stable azole resistance by Candida glabrata isolates obtained before the clinical introduction of fluconazole. Antimicrob Agents Chemother 2005; 49:783-7.

12. Magill SS, Shields C, Sears CL et al. Triazole cross-resistance among Candida spp.: case report, occurrence among bloodstream isolates, and implications for antifungal therapy. J Clin Microbiol 2006; 44:529-35.
13. CLSI 2008. Reference method for broth dilution antifungal susceptibility testing of yeasts. Approved standard, 2nd ed. NCCLS document M27-A3. NCCLS, Wayne, PA.

14. Alexander BD, Byrne TC, Smith KL et al. Comparative evaluation of Etest and sensititre yeastone panels against the Clinical and Laboratory Standards Institute M27-A2 reference broth microdilution method for testing Candida susceptibility to seven antifungal agents. J Clin Microbiol 2007; 45:698-706.

15. Chryssanthou E. Trends in antifungal susceptibility among Swedish Candida species bloodstream isolates from 1994 to 1998: comparison of the E-test and the Sensititre Yeast One colorimetric antifungal panel with the NCCLS M27-A reference method. J Clin Microbiol 2001; 39:4181-3.

16. Catón E, Pemán J, Valentin A et al. Evaluation and utility of the Etest and NeoSensitabs methods in studding fluconazole yeast susceptibility. Rev Esp Quimioterap 2006; 19:267-74.

17. Morace G, Amato G, Bistoni F et al. Multicenter comparative evaluation of six commercial systems and the national committee for clinical laboratory standards M27-A2 broth microdilution method for fluconazole susceptibility testing of Candida species. J Clin Microbiol 2002; 40:2953-58.

18. Chang HC, Chang JJ, Chan SH et al. Evaluation of Etest for direct antifungal susceptibility testing of yeasts in positive blood cultures. J Clin Microbiol 2001; 39:1328-33.

19. Barry AL, Pfaller MA, Rennie RP et al. Precision and accuracy of fluconazole susceptibility testing by broth microdilution, Etest, and disk diffusion methods. Antimicrob Agents Chemother. 2002; 46:1781-17814.

20. Diekema JD, Messer AS, Hollins RJ et al. Evalution of Etest and disk diffusion methods compared with broth microdilution antifungal susceptibility testing of clinical isolates of Candida spp. against posaconazole. J Clin Microbiol 2007; 45:1974-7.

21. Nguyen, MH, CJ Clancy, VL Yu. Do in vitro susceptibility data predict the microbiologic response to amphotericin B? Results of a prospective study of patients with Candida fungemia. J Infect Dis1998; 177:425-30.

22. Colombo AL, Nucci M, Park BJ et al. Brazilian Network Candidemia Study. Epidemiology of candidemia in Brazil: a nationwide sentinel surveillance of candidemia in eleven medical centers. J Clin Microbiol 2006; 44:2816-23.

23. Tortorano AM, Peman A, Bernhardt L et al. Epidemiology of Candidaemia in Europe: results of 28 month European Confederation of Medical Mycology (ECMM) Hospital based surveillance study. Eur Clin Microbiol Infect Dis 2004; 23:31722.

24. Richet H, Roux P, Des Champs C et al. French Candidemia Study Group. Candidemia in French hospitals: incidence rates and characteristics. Clin Microbiol Infec Dis 2002; 8:405-12.

25. Cuenca-Estrella M, Almirante B, Rodríguez D et al. Epidemiology and predictors of mortality in cases of Candida bloodstream infection: results from population-based surveillance, Barcelona, Spain, from 2002 to 2003. J Clin Microbiol 2005; 43:1829-35.

26. Pemán J, Catón E, Gobernado M et al. Epidemiology and antifungal susceptibility of Candida species isolated from blood: results of a 1-year multicentre study in Spain. Eur J Clin Microbiol Infec Dis 2005; 24:23-30.

27. Macphail GL, Taylor GD, Buchanan-Chell M et al. Epidemiology, treatment and outcome of candidemia: a five-year review at three Canadian hospitals. Mycoses 2002; 45:141-5.

28. Aquino VR, Lunardi LW, Goldani LZ et al. Prevalence, susceptibility profile for fluconazole and risk factors for candidemia in a tertiary care hospital in southern Brazil. Braz J Infect Dis 2005; 9:411-8. 
29. Godoy P, Tiraboschi IN, Severo LC et al. Species distribution and antifungal susceptibility profile of Candida spp. Blood stream isolates from Latin American hospitals. Mem Inst Oswaldo Cruz 2003; 98:401-5.

30. Krcmeryb V, Barnes. AJ. Non-albicans Candida spp. causing fungaemia: pathogenicity and antifungal resistance. J of Hosp Infec 2002; 50:243-60.

31. Brito LR, Guimarães T, Nucci M. Clinical and microbiological aspects of candidemia due to Candida parapsilosis in Brazilian tertiary care hospitals. Med Mycol 2006; 44:261-6.

32. Levin AS, Costa SF, Mussi NS et al. Candida parapsilosis fungemia associated with implantable and semi-implantable central venous catheters and the hands of healthcare workers. Diagn Microbiol Infect Dis 1998; 30:243-9.

33. Bassetti M, Righi E, Costa A et al. Epidemiological trends in nosocomial candidemia in intensive care. BMC Infect Dis 2006; 6:1-6.

34. Girão E, Levim A S, Basso M et al. Seven-year trend analysis of nosocomial candidemia and antifungal (fluconazole and caspofungin) use in Intensive Care Units at a Brazilian University Hospital. Med Mycol 2008; 46:581-8.

35. Pasqualotto AC, Zimerman R, Aquino VR et al. Take control over your fluconazole prescription: The growing importance of Candida glabrata as an agent of candidemia in Brazil. Infect Control Hosp Epidemiol 2008; 29:898-9.

36. Pfaller MA, Boyken L, Hollis R J et al. In vitro Susceptibility of Invasive Isolates of Candida spp. to Anidulafungin, Caspofungin, and Micafungin: Six Years of Global Surveillance. J Clin Microbiol 2008; 46:150-6.

37. Pfaller MA, Diekema MG, Ostrosky-Zeichner L et al. Correlation of MIC with outcome for Candida species tested against Caspofungin, Anidulafungin: analysis and propsal for interpretative MIC breakpoints. J Clin Microbiol 2008; 2008; 46:2620-29.

38. Effron-Garcia G, Katiyar SK, Park S et al. A Naturally Occurring Proline-to-Alanine Amino Acid Change in Fks1p in Candida parapsilosis, Candida orthopsilosis, and Candida metapsilosis Accounts for Reduced Echinocandin Susceptibility. Antimicrob Agents Chemother 2008; 52:2305-12.
39. Pfaller MA, Diekema DJ, Jones RN et al. Bloodstream Infections Due to Candida Species: SENTRY Antimicrobial Surveillance Program in North America and Latin America, 1997-1998. Antimicrob Agents Chemother 2000; 44:747-51

40. Pfaller MA, Diekema MG, Gibbs DL, et al. Geographic and temporal trends in isolation and antifungal susceptibility of Candida parapsilosis: a global assessment from the ARTEMIS DISK antifungal surveillance program 2001 to 2005. J Clin Microbiol 2008; 46:842-49.

41. Pfaller MA, Diekema MG, Jones RN et al. International surveillance of bloodstream infections due to Candida species: frequency of occurrence and in vitro susceptibilities to fluconazole, voriconazole and voriconazole of isolates collected from 1997 through 1999 in SENTRY antimicrobial surveillance program. J Clin Microbiol 2001, 39:3254-9.

42. Pfaller MA, Diekema MG, Rinaldi MG et al. Results from the ARTEMIS DISK global antifungal surveillance study: a 6.5-year analysis of susceptibilities of Candida and other yeast species to fluconazole and voriconazole by standardized disk diffusion testing. J Clin Microbiol 2005; 43:584859.

43. Ostrosky-Zeichner L, Rex JH, Pappas PG et al. Antifungal susceptibility survey of 2,000 bloodstream Candida isolates in the United States. Antimicrob Agents Chemother 2003; 47:3149-54.

44. Pfaller MA, Messer SA, Boyken L et al. Selection of a Surrogate Agent (Fluconazole or Voriconazole) for Initial Susceptibility Testing of Posaconazole against Candida spp.: Results from a Global Antifungal Surveillance Program. J Clin Microbiol 2008; 46:551-9.

45. Epinel-Ingroff A, Barchiesi F, Cuenca-Estrella M. Comparison of visual 24 hour and spectrophotometric 48 hour MICs to CLSI reference microdilution MICs of fluconazole, itraconazole, posaconazole and voriconazole for Candida spp., a collaborative study. J Clin Microbiol 2008; 43:4535-40. 